УДК 911.372.31: 902.2 «637.7» (477.51)

DOI: https://doi.org/10.33782/eminak2020.1(29).398

\title{
О ДВУХ ТРАДИЦИЯХ ПРОИЗВОДСТВА МЕТАЛЛИЧЕСКИХ БРИТВ С РАЗДВОЕННЫМИ ИЛИ УСЕЧЕННЫМИ КОНЦАМИ В БРОНЗОВОМ ВЕКЕ 1
}

\author{
Юрий Черниенко \\ Одесский археологический музей НАН Украины (Одесса, Украина) \\ e-mail: oamnanu@mail.ru \\ ORCID: https://orcid.org/0000-0001-8710-7481
}

У статті виділені дві традиції виробництва металевих бритв з роздвоєними або тупими кінцями у бронзовому віці, виходячи з розмірів вирізів. Перші пов'язані з невідповідними культурно-територіальними контекстами.

Ключові слова: бритви з роздвоєними або усіченими кінцями, традиції виробництва, культурно-територіальні контексти

В последнее время возрос интерес исследователей к таким своеобразным изделиям как металлические бритвы бронзового века. Нередко в археологической литературе бритвами могут называться различные предметы. Здесь рассматриваются только бритвы с раздвоенными или усеченными концами. Эти изделия распространены на огромной территории, хотя соответствующие находки в Восточной Европе относительно редки.

В.С. Бочкарев, в противовес дробной классификации бритв, предложенной И.Ж. Тутаевой ${ }^{2}$ да и типологии, разработанной прежде им совместно с А.М. Лесковым³ , в недавних работах выделяет всего два генетически связанных типа бритв с раздвоенными концами: один (терешковский) - бритвы с полукруглым или полуовальным вырезом в верхней части клинка и кольцевидным упором в основании черенка, другой (вязовок) - бритвы с полукруглым вырезом в верхней (наиболее широкой) части клинка, круглым отверстием ниже выреза и кольцевидным упором на черенке4.

Автор этих строк предпочитает говорить о почти соответствующих (во всяком случае, обобщенным изображениям выделяемых В.С. Бочкаревым типов 5 двух, ве-

\footnotetext{
1 В сборнике «Древности Восточной Европы, Центральной Азии и Южной Сибири в контексте связей и взаимодействий в евразийском культурном пространстве (новые данные и концепции): Мат. Междунар. конф. Т. ІІ. Связи, контакты и взаимодействия культур Северной Евразии и цивилизаций Востока в эпоху палеометалла (IV-I тыс. до н.э.). К 80-летию со дня рожд. выдающегося археолога В.С. Бочкарева» (Санкт-Петербург: ИИМК РАН, Невская типография, 2019. С. 186-189) опубликованы почти одноименные краткие тезисы с неудовлетворительной редакторской правкой, существенно исказившей смысл.

2 См., напр.: Тутаева И.Ж. Металлические бритвы эпохи поздней бронзы Восточной Европы // Российский археологический ежегодник. 2014. № 4. С. 175-193.

3 Bočkarev, V.S., Leskov, A.M. Jung- und spätbronzezeitliche Gussformen im nördlichen Schwarzmeergebiet. Prähistorische Bronzefunde. Abt.XIX. Bd.1. München: C. H. Beck'sche Verlagsbuchhandlung, 1980. S. 62-63.

4 См., напр.: Бочкарев В.С. Этапы развития металлопроизводства эпохи поздней бронзы на юге Восточной Европы // Stratum plus. 2017. № 2. С. 171-174, 183; С. 172, рис. 9: 12; С. 173, рис. 10: 18; C. 178, 180-182, 191, 193, табл. 1: типы 55, 73.

5 См.: Ibid. С. 172, рис. 9: 12; С. 173, рис. 10: 18; С. 178, 180-182, 191, 193, табл. 1: типы 55, 73.
} 
роятно, генетически связанных традициях (в каждую из которых входят бритвы нескольких типов классификации И.Ж. Тутаевой), но исходя из другого критерия размера выреза. Отверстие под вырезом бритвы (отделенное от последнего) - редкость. Поэтому автор предпочел бы не изображать первое в обобщенных схематических иллюстрациях типов бритв. Показательно, что И.Ж. Тутаева отнесла к одному и тому же типу (вязовковскому) негативы бритв с крупными вырезами, причем круглое отверстие было предусмотрено лишь в одном (правда, вопреки ее мнению) случае, а к другому (лысогорскому) - негатив, с точки зрения исследовательницы, бритвы с символическим по глубине вырезом и отверстием под последним 6 .

Типология В.С. Бочкарева почему-то охватывает бритвы лишь с кольцевым упором, хотя таковые есть с плоским упором (рис. 1: 7, 9), без упора (рис. 1:2, 19), не говоря уже о фрагментарных находках, у которых черенки не представлены (рис. 1: 3, $117,12,15)$.

Между тем, размерами вырезов различаются также бритвы бронзового века Средней и Западной Европы, причем заметна тенденция к укрупнению выемок со временем $^{8}$. Впрочем, исследователи пишут о существенных отличиях большинства из этих бритв от более восточных 9 . Что касается последних, то В.С. Бочкарев в некоторых работах делает упор на хронологическую позицию выделяемых типов соответствующих и других восточноевропейских изделий и комплексов ${ }^{10}$, тогда как автор этих строк считает принципиальным, помимо этого, акцентировать внимание на несовпадающие культурно-территориальные контексты для металлических бритв с раздвоенными или усеченными концами двух рассматриваемых здесь традиций. Впрочем, и В.С. Бочкарев, считая бритвы терешковского типа характерными для IV (лобойковско-дербеденовской) группы/периода развития металлопроизводства эпохи поздней бронзы на юге Восточной Европы, по мнению первого (во всяком случае, былому), существовавшей в рамках одноименной зоны металлопроизводства и связанной с археологическими культурами черкаскульской, сусканской, бережновско-маевской срубной, сабатиновской и Ноуа, а типа вязовок - для V (красномаяцкой) группы (точнее - для нижнеднепровской подгруппы последней), по мнению исследователя (во всяком случае, былому), принадлежавшей красномаяцкому очагу металлообработки, в основном обслуживавшему население поздней сабатиновской культуры, тем самым ведет речь о культурно-территориальных контекстах, не совпадающих не только во времени ${ }^{11}$.

\footnotetext{
6 См., напр.: Тутаева И.Ж. Металлические бритвы... С. 182, 184, 187, 190; С. 178, 179, рис. 1: 14, 15, 19.

7 Реконструкция черенка бритвы, отливавшейся в мастерской Бэлэнешть, как непременно имевшего кольцевидный упор (Сава Е. К вопросу о литейных формах для отливки бронзовых бритв // Culturi, Procese şi Contexte în Arheologie. Volum omagial Oleg Leviţki la 60 de ani. Chişinău, 2016. С. 160 , рис. 2: 3, 4) вряд ли убедительна.

${ }^{8}$ Jockenhövel A. Die Rasiermesser in Mitteleuropa (Süddeutschland, Tschechoslowakei, Österreich, Schweiz). Prähistorische Bronzefunde. Abt. VIII. Bd. 1. München: C.H. Beck'sche Verlagsbuchhandlung, 1971. Taf. 82; Jockenhövel A. Die Rasiermesser in Westeuropa (Westdeutschland, Niederlande, Belgien, Luxemburg, Frankreich, Großbritannien und Irland). Prähistorische Bronzefunde. Abt. VIII. Bd. 3. München: C. H. Beck'sche Verlagsbuchhandlung, 1980. Taf. 104.

${ }^{9}$ См., напр.: Подобед В.А., Усачук А.Н., Цимиданов В.В. Погребение срубной культуры из Комсомольского (Астраханская область): некоторые аспекты осмысления // Археология нижнего Поволжья: проблемы, поиски, открытия. Астрахань: Астраханский ун-т, 2010. URL: http://astraheritage.newsujet.com/Material/48/91

10 См., напр.: Бочкарев В.С. Этапы развития... С. 159-163, 168-183.

11 ibid. С. $171-174,183$; С. 172, рис. 9: 12; С. 173, рис. 10: 18; С. 178, 180-182, табл. 1: типы 55, 73.
} 

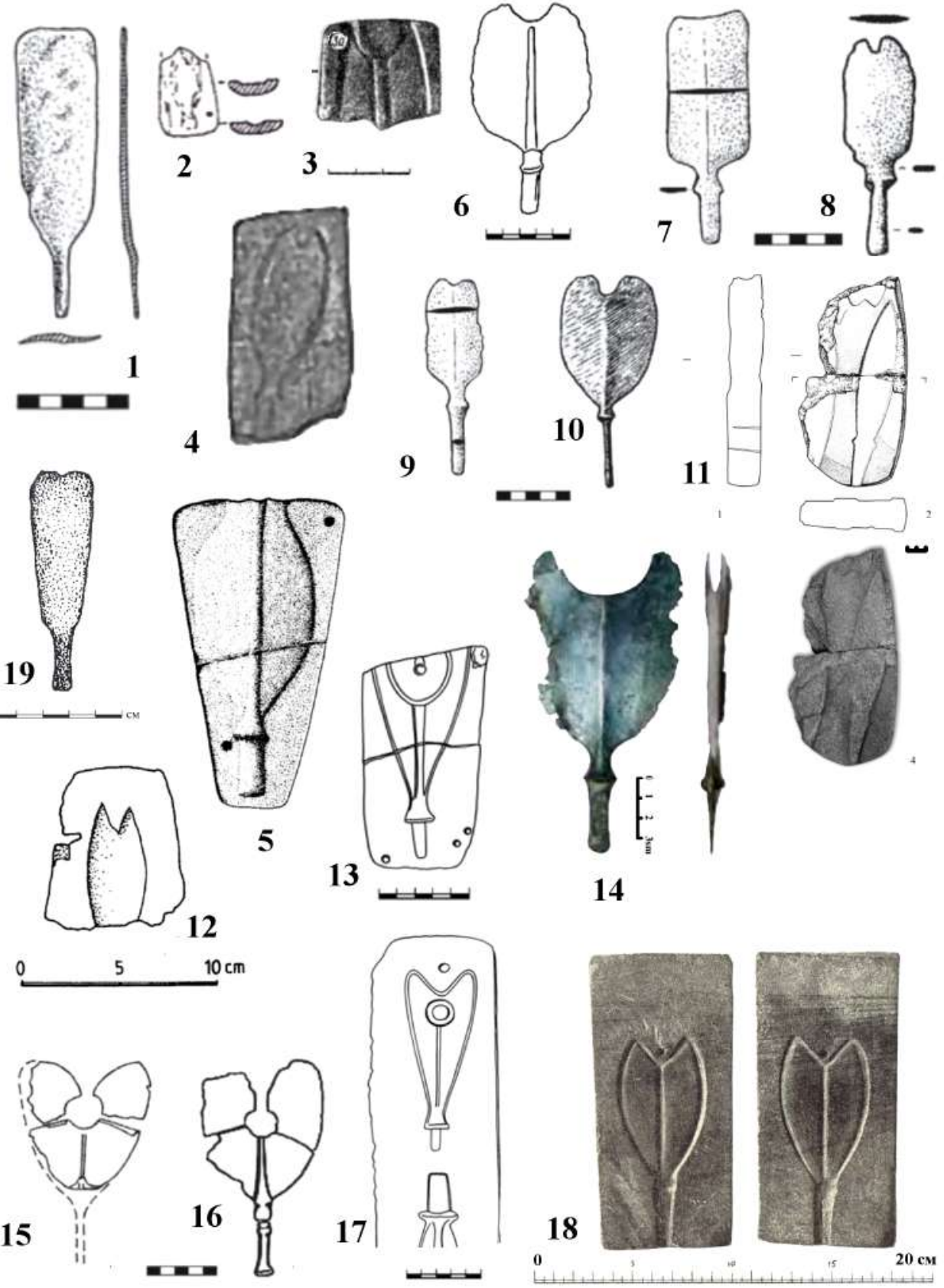

Рис. 1. Бронзовые бритвы $(1,6-10,14-16,19)$ и негативы бритв на каменных литейных формах (25, 11-13, 17, 18): 1 - Михайловка (по: Тутаева (2014). Рис. 1: 1); 2 - Капитаново-1 (по: Бровендер 2000. Рис. 3: III); 3 - Голоуров (по: Шарафутдінова 1973. Рис. 1: 3a); 4 - «Черкасский комплекс» (по фото, предоставленному С.А. Агаповым); 5 - Деревянное (по: Bočkarev, Leskov 1980. Taf. 2: 17b); 6 Лобойковка (по: Дергачев 2013. Илл. 5: 1); 7 - Высокое (по: Тутаева 2014. Рис. 1: 2); 8 - Комсомольский (по: Тутаева 2014. Рис. 1: 5); 9 - Дербедень (по: Тутаева 2014. Рис. 1: 3); 10 - Алтай (по: Тутаева 2014. Рис. 1: 4); 11 - Бэлэнешть (по: Sava 2011. Abb. 5: 2, 4); 12 - Турень (по: Boroffka 1997. Abb. 2: 3a); 13 - Волошское 1 (по: Дергачев 2011. Рис. 151: 8); 14 - Беленькое (по: Клочко, Козыменко 2017. Ил. 29); 15 - Бэлень (по: Тутаева 2014. Рис. 1: 17); 16 - Вырбица (по: Тутаева 2014. Рис. 1: 18); 17 - Вязовок (по: Дергачев 2011. Рис. 151: 10); 18 - Макарьевское (по: Дмитриев 1930. Табл. II, рис. 2); 19 - Кривой Рог, «Царева могила» (по: Кузнецов, Мочалов 2014. Рис. 4: 4). 
Последние выглядят еще более разнящимися при выделении, наряду с лобойковско-дербеденовской, группы металлопроизводства Липовень-Бэлэнешть IV периода и связи культуры Ноуа-II только с рышештской группой металлопроизводства $^{12}$ (что представляется и более корректным, чем, например, связывать мастерскую Бэлэнешть и некоторые ранние клады культуры Ноуа с лобойковскодербеденовской зоной металлопроизводства, а некоторые более поздние клады той же культуры, в частности, Бэлень и Рышешть, - с красномаяцким очагом металлообработки ${ }^{13}$ ), учитывая и количественное соотношение бритв (вместе с соответствующими негативами) разных культур в каждом из этих периодов. Так, автору неизвестны указанные изделия лобойковско-дербеденовской зоны металлопроизводства, которые бы достоверно относились к сабатиновской культуре, а в культуре Ноуа к близкой традиции относится как будто бы лишь часть негатива на одной из литейных форм мастерской Бэлэнешть (рис. 1: 11).

Культурная атрибуция бритв, предложенная И.Ж. Тутаевой ${ }^{14}$, не для всех типов представляется убедительной.

Еще менее четко культурно дифференцированы восточноевропейские бритвы в работах других исследователей. Впрочем, исходя из иллюстрации Е.Н.Черных, для бритв западной зоны общности культур валиковой керамики характерны более крупные вырезы, чем для соответствующих изделий восточной ${ }^{15}$. Это вполне согласуется и с нынешними данными. «В самом общем виде можно полагать, что восточная зона общности КВК входила целиком в Евразийскую металлургическую провинцию, западная и контактная зоны - в Европейскую» ${ }^{16}$. «Завадово-лобойковский 17 очаг в целом теснее связан с ЕАМП» ${ }^{18}$. Контактная зона ОКВК ранней фазы представлена прежде всего сабатиновской культурой ${ }^{19}$. Бритвы и по нынешним данным далеко не самые характерные для последней изделия. Неудивительно поэтому, что среди предметов, характеризующих контактную зону ОКВК, на иллюстрации Е.Н. Черных нет ни одного изображения бритвы ${ }^{20}$. Но в этом контексте уместно вспомнить, помимо негатива на одной из литейных форм мастерской Волошское 1 ,

\footnotetext{
12 Бочкарев В.С., Кашуба М.Т. Культурно-историческая ситуация на юге Восточной Европы накануне эпохи железа // Stratum plus. 2018. № 3. С. 209.

13 См., напр.: Бочкарев В.С. Этапы развития... С. 171-174; С. 178, 180-182, табл. 1: IV, V.

14 Тутаева И.Ж. Металлические бритвы... С. 184-185.

15 См.: Черных Е.Н. Проблема общности культур валиковой керамики в степях Евразии // Бронзовый век степной полосы Урало-Иртышского междуречья. Челябинск: Башкирский госуниверситет, 1983. С. 82, 86-87; С. 92, рис. 9: 1, 2, 16, 30, 40, 53. Этому не противоречат и иллюстрации B.А. Дергачева, судя по которым, к западным из восточноевропейских бритв по размерам выреза примыкают также отливавшиеся в мастерской Волошское 1 и в матрице из с. Вязовок (см., напр.: Дергачев В. Клады поздней бронзы из сс.Жавгур и Отак в Республике Молдова // Revista Arheologică. 2013. S.n., vol. IX. Nr. 2. C. 172, илл. 4; 5).

16 Черных Е.Н. Проблема общности... С. 90.

17 Позднее Е.Н. Черных корректнее писал о лобойковском очаге металлообработки с ранними в пределах ОКВК изделиями (Черных Е.Н. Проблема общности... С. 95), который и имеет здесь в виду автор этих строк.

18 Черных Е.Н. Древняя металлообработка на Юго-Западе СССР. Москва: Наука, 1976. С. 172.

19 Черных Е.Н. Проблема общности... С. 82, 95.

20 Ibid. C. 92, рис. 9.
} 
бритву с крупным вырезом, найденную у с. Беленькое Белгород-Днестровского р-на Одесской обл. (рис. 1: 13, 1421).

Не рассматривая здесь больше средне- и западноевропейские бритвы, по поводу более восточных подчеркнем, что именно размерами выреза бритвы, связанные с разными культурно-территориальными контекстами, в основном разнятся.

Исходя из большинства публикаций бритв и негативов таковых, представляется целесообразным и принципиальным «объединить» наблюдения Е.Н.Черных, В.С. Бочкарева и В.А. Дергачева. В сабатиновскую эпоху бритвы с вырезом не глубже, чем у отливавшихся в Голоуровской мастерской (включая последние), вплоть до усеченного конца вместо такового, в основном были характерны для Евразийской металлургической провинции (в частности, лобойковско-дербеденовской зоны металлопроизодства ${ }^{22}$ ) - восточной зоны общности культур валиковой керамики ${ }^{23}$ (в частности, бережновско-маевской срубной культуры ${ }^{24}$, которой (в основном) принадлежал лобойковско-голоуровский очаг металлообработки ${ }^{25}$ ), будучи известны вплоть до Алтая на востоке (рис. 1: 3-10).

Из бритв покровской ${ }^{26}$ или покровской срубной культуры срубной культурноисторической области или общности как минимум представленная соответствующим, похоже, негативом на литейной форме из не самого позднего горизонта первой поселения Капитаново-1 имеет небольшой вырез27 (рис. 1:2).

Автор, как и ранее 28 , сходится во мнениях с теми исследователями, которые считают досабатиновскими конец раннего, если не начало среднего, периода Мосоловского поселения ${ }^{29}$, с которым Ю.М.Бровендер синхронизирует контекст находки «литейной формы с незавершенным негативом ножа-бритвы» на поселении Капи-

\footnotetext{
21 Возражение против отнесения В.И. Клочко и А.В. Козыменко бритвы, найденной у с. Беленькое, к лобойковской группе, связываемой ими лишь с бережновско-маевской срубной культурой (Клочко В.И., Козыменко А.В. Древний металл Украины. Киев, 2017. С. 146, ил. 29), см.: Черниенко Ю.А. Лобойковско-голоуровская металлургия и население степного Дунай-Днестровского междуречья // Народы и культуры Нижнего Дуная в древности. Мат. междунар. науч.-практ. конф. (г. Измаил, 23-26 августа 2018 г.). Измаил: Ирбис, 2018. С. 100.

22 См., напр.: Бочкарев В.С. Этапы развития... С. 171-173; С. 172, рис. 9: 12; С. 178, 180, 181, табл. 1 : mun 55.

${ }_{23}$ См., напр.: Черных Е.Н. Проблема общности... С. 82, 86-87, 90, 94, 95; С. 92, рис. 9: 16, 30, 40, 53.

${ }^{24}$ См., напр.: Бочкарев В.С. Этапы развития... С. 171-173; С. 178, 180, 181, табл. 1: тип 55.

25 См., напр.: Бочкарев В.С. Срубно-алакульская зона металлопроизводства эпохи поздней бронзы // Археология Восточно-Европейской степи. Межвуз. сб. науч. тр. Вып. 10. Саратов: Типография ИП Беглакова Е.С., 2013. С. 75; Черниенко Ю.А. Сабатиновская культура в системе древностей бронзового века юга Восточной Европы // Stratum plus. 2014. № 2. C. 34; Клочко B.I. Озброєння та військова справа давнього населення України (5000-900 рр. до Р.Х.). Київ: АртЕк, 2006. С. 192-195, 197-198, 251, 253, 256-257, 268, 273, 307-308; Отрощенко В.В. Проблеми періодизації культур середньої та пізньої бронзи півдня Східної Європи (культурно-стратиграфічні зіставлення). Київ: Інститут археології НАН України, 2001. С. 160-162, 171.

26 Тутаева И.Ж. Металлические бритвы... С. 185.

27 Бровендер Ю.М. Капитаново-1. Поселение Покровской срубной культуры в северскодонецком Левобережье // Старожитності степового Причорномор'я і Криму. T. VIII. Запоріжжя: Дике поле, 2000. С. 181; С. 177, рис. 3: III. Небольшое углубление на конце бритвы из погребения покровской срубной культуры Старая Тойда 1/8, судя по фото, скорее похоже на изъян (см.: Корнюшин Г.И. Курганы эпохи поздней бронзы у с. Старая Тойда Воронежской области // Краткие сообщения Института археологии АН СССР. 1971. Вып. 127. С. 80, 82; С. 83, рис. 34: 9).

28 Черниенко Ю.А. Сабатиновская культура... С. 15, 16, 40, 42, 44-47, 54, 58-69, 71-82.

29 См., напр.: Отрощенко В.В. Проблеми періодизації... С. 143, 164.
}

Eminak, 2020, 1 (29) 
таново-1, и первый период БМСК30, который (действительно синхронный, и по мнению автора этих строк, концу раннего - началу среднего периода Мосоловского поселения) Ю.М. Бровендеру позволяет синхронизировать со слоем III периода поселения Капитаново-1 почему-то именно эта найденная там матрицаз1, хотя В.В. Отрощенко, концепции которого, как известно, следует Ю.М. Бровендер в периодизации срубной культурно-исторической общности, считает бритвы показательными для второго периода БМСК 32 . Кроме того, известны изделия с усеченными концами или небольшими выемками эпохи ранней бронзы (зачастую ямной культуры) ${ }^{33}$, по крайней мере часть из которых ряд исследователей более или менее уверенно счел бритвами ${ }^{34}$ (рис. $1: 1,19$ ).

Утверждения о появлении бритв на юге Восточной Европы в III периоде эпохи поздней бронзы, по схеме В.А. Дергачева и В.С. Бочкарева ${ }^{35}$, при полном отсутствии комплексов раннесрубного времени с данными предметами ${ }^{36}$, или в IV периоде развития металлопроизводства эпохи поздней бронзы в этом регионе, по обновленной схеме В.С. Бочкарева 37 , «как бы внезапно и неоткуда»38, таким образом, неправомерны. Более того, генетическую связь лобойковско-дербеденовского металлокомплекса с более ранними срубными типами ${ }^{39}$ как будто-бы подтверждает и эта категория изделий.

Бритвы с вырезом глубже, чем у отливавшихся в Голоуровской мастерской, или с близким по глубине к таковому у последних, но с более широким присущи рышештско-красномаяцко-дичевской (в основном) зоне металлопроизводства (в частности,

\footnotetext{
30 См., напр.: Ромашко В.А. Заключительный этап позднего бронзового века Левобережной Украины (по материалам богуславско-белозерской культуры). Киев: КНТ, 2013. С. 390.

31 Бровендер Ю.М. Капитаново-1... С. 181; С. 177, рис. 3: III.

32 См., напр.: Отрощенко В.В. Історія племен зрубної спільності. Автореф. дис... д-ра іст. наук. Київ, 2002. C. 19.

33 См., напр.: Кузнецов П.Ф., Мочалов О.Д. Особый тип металлических изделий ямной культуры (по результатам работ в Самарской долине) // Известия самарского научного центра Российской академии наук. Гуманитарные науки. Т. 16. № 3. Самара: Изд-во СНЦ РАН, 2014. С. 295-297; С 295, рис. 3: 2, 3; С. 296, рис. 4: 1, 2, 4, 7; Шапошникова О.Г. Ямная культурно-историческая общность // Археология Украинской ССР. В трех томах. Т. 1. Первобытная археология. Киев: Наук. думка, 1985. С. 342-343, рис. 95: 1; Кореневский С.Н. О металлических ножах ямной, полтавкинской и катакомбной культур // Советская археология. 1978. № 2. С. 36; С. 37, рис. 4: 9.

${ }^{34}$ См., напр.: Братченко С.Н. До проблеми ранньобронзової індустрії Східної Європи // Древние культуры Восточной Украины (проблемы изучения и правовой охраны археологического наследия): Сб. науч. тр. Луганск: Изд-во ВУГУ, 1996. С. 40, 43, 45; С. 41, рис. 5: 13; С. 44, рис. 7: 2, 12; Латынин Б.А. Молоточковидные булавки, их культурная атрибуция и датировка (Археологический сборник Государственного Эрмитажа, Вып. 9). Ленинград, 1967. С. 72-75; Тутаева И.Ж. Металлические бритвы... С. 179, 192; С. 178, 179, рис. 1: 1; Бобринской А.А. Отчет о раскопках в Киевской губернии в 1911 году // Известия Императорской Археологической Комиссии. 1913. Вып. 49. С. 93, рис. 1; ср.: Кузнецов П.Ф., Мочалов О.Д. Особый тип металлических изделий... С. 297.

35 Дергачев В.А., Бочкарев В.С. Металлические серпы поздней бронзы Восточной Европы. Кишинев: Высшая антропологическая школа, 2002. С. 12-13, рис. 1.

36 Подобед В.А., Усачук А.Н., Цимиданов В.В. Погребение срубной культуры...

37 См., напр.: Бочкарев В.С. Этапы развития... С. 171-173 и сл.

38 Бочкарев В.С., Тутаева И.Ж. Прорезные наконечники копий эпохи поздней бронзы Восточной Европы и сопредельных территорий // Stratum plus. 2019. № 2. С. 187.

39 См., напр.: Бочкарев В.С. К вопросу об использовании серпов и серповидных орудий в степных (скотоводческих) культурах эпохи поздней бронзы Восточной Европы // Российский археологический ежегодник. 2012. № 2. С. 197-201.
} 
красномаяцкому очагу металлообработки ${ }^{40}$ ) Европейской металлургической провинции - в той или иной мере некоторым культурам западной ${ }^{41}$ и контактной зон ОКВК (в частности, Ноуа, Сабатиновка ${ }^{42}$, Кослоджень ${ }^{43}$ ) (рис. 1: 13-16). Первые найдены и за пределами ареала блока культур Сабатиновка-Ноуа-Кослоджень, но восточнее Украины, кажется, лишь у бритв из Воронежской обл. и представленной негативами двухчастной литейной формы, найденной у с. Макарьевское Курганской обл., выемки сравнительно крупные ${ }^{44}$ (рис. 1: 17, 18).

Но все же самые крупные вырезы присущи соответствующим изделиям из Украины и более западных стран (рис. 1: 13-17). Так, негатив, в том числе бритвы с довольно крупной выемкой, имеется на литейной форме красномаяцкой группы ${ }^{45}$, найденной у с. Вязовок Днепропетровской обл.46 (рис. 1: 17) - недалеко от ареала сабатиновской культуры, в частности, от мастерской Волошское 1 той же группы, где, помимо прочего, тоже найдена матрица с негативом бритвы с крупным вырезом ${ }^{4}$ (рис. 1: 13). Это свидетельствует о влиянии этой культуры на соседнее население (возможно, этапа прото-ББ богуславско-белозерской культуры ${ }^{48}$ ).

В традиции, близкой к лобойковско-голоуровской и более восточным, отливались бритвы в мастерской Бэлэнешть раннего этапа культуры Ноуа ${ }^{49}$ (рис. 1: 11) и в матрице с поселения Турень развитого этапа культуры Витенберг 50 (рис. 1: 12). Датировка этой мастерской говорит о времени внедрения в Карпато-Дунайский регион бритв с раздвоенными концами вообее, но таковые «типа Бэлень», правда, судя пока лишь по двум комплексам, в которых представлены как типы бритв с крупными вырезами (рис. 1: 13, 15), так и изделия других категорий, дающие представления о хронологии, - кладу Бэлень и мастерской Волошское 1, появляются позже по-видимому, в период $\mathrm{BrD}$, или, по обновленной схеме B.C. Бочкарева, в пятый51,

\footnotetext{
40 См., напр.: Бочкарев В.С. Этапы развития... С. 173-174; С.173, рис. 10: 18; С. 178, 181-182, 193, табл. 1: тип 73.

41 См., напр.: Черных Е.Н. Проблема общности... С. 87, 90; С. 92, рис. 9: 1, 2.

42 См., напр.: Бочкарев В.С. Этапы развития... С. 173-174; С.173, рис. 10: 18; С. 178, 181-182, 193, табл. 1: тип 73.

${ }_{43}$ См., напр.: Дергачев В. Клады поздней бронзы... С. 169, 172-174; С. 172, илл. 4; 5: 8, 10-14; С. 173, илл. 6: 4, 9, 11, 13-16.

${ }_{44}$ См., напр.: Тутаева И.Ж. Металлические бритвы... С. 182, 184, 185, 187, 189, 190; С. 177, табл. 1; С. 178,179 , рис. $1: 14$; С. 182 , рис. $2: 3$, 4, 7; С. 183, рис. $3: 1-3$; С. 186, 187, рис. $4: 11,19,22,25,26$.

45 Ср.: Черных Е.Н. Древняя металлообработка... С. 140 и др.; Черниенко Ю.А. Сабатиновская культура... С. 25.

46 См., напр.: Бочкарев В.С. Периоды развития металлопроизводства эпохи поздней бронзы на юге Восточной Европы // Археология восточно-европейской степи. Межвуз. сб. науч. тр. Вып. 12. Саратов: Техно-Декор, 2016. С. 120, 123; С. 154, табл. I: 122; С. 157, рис. 5.

47 См., напр.: Bočkarev V.S., Leskov A.M. Jung- und spätbronzezeitliche Gussformen... No. 30.

48 Ромашко В.А. Заключительный этап... С. 97, 99; С. 506, 528, рис. 115: 7.

49 См., напр.: Дергачев В. Клады поздней бронзы... С. 173-174; С. 173, илл. 6: 12.; Дергачев В.А. Топоры-кельты поздней бронзы Карпато-Подунавья. Вып. 2. Кельты и серпы Нижнего Подунавья. Кишинэу: Изд.-Полигр. Фирма «Центральная Типография», 2011. С. 231, 235, 248, 252, 268, 276; С. 222 , рис. $140: 23-24$; С. 231 , рис. $146: 8$; С. 236 , рис. 150 : 3; С. 247, рис. 156: 56; С. 248, рис. 157: 28.

50 См., напр.: Boroffka N.G.O. Rasiermesser der Bronze- und Hallstattzeit aus Rumänien // Хроvоৎ. Beiträge zur Prähistorischen Archäologie zwischen Nord- und Südosteuropa. Festschrift für Bernhard Hänsel. - Internationale Archäologie. Studia honoraria. Bd. 1. Espelkamp: Verlag Marie Leidorf GmbH, 1997. S. 564, 570, 573; s. 568, abb. $2: 3 a$.

51 Ср.: Тутаева И.Ж. Металлические бритвы... С. 185, 187.
} 
относясь, пусть и к производной от восточных традиций 2 , не прижившихся в сабатиновское время в этом регионе, но все же к иной, в понимании автора этих строк, традиции.

Е. Сава и Н. Бороффка относят мастерскую Бэлэнешть «к ингуло-красномаяцкому (или рышшть-красномаяцкому) очагу металлообработки» на основании материала для изготовления литейных форм - талькового сланца, обеспечивавшего технологию производства высококачественных оловянистых бронз 53 .

В.С. Бочкарев назвал рышештско-красномаяцкой металлообрабатывающую зону, включавшую, в частности, сходные рышештский и красномаяцкий (с убедительным разъяснением того, почему не «ингуло-красномаяцкий») очаги металлообработки ${ }^{54}$.

Выделение группы металлопроизводства Липовень-Бэлэнешть55, возможно, имеет смысл, но автор этих строк предпочел бы рассматривать ее в рамках ранней стадии рышештского очага металлообработки, когда формировавшаяся рышештско-красномаяцко-дичевская зона металлопроизводства еще находилась под мощным влиянием лобойковско-голоуровского очага ${ }^{56}$. И дело не в материале для изготовления литейных форм. Лобойковско-голоуровские литейщики тоже использовали матрицы из хлорито-талько-амфиболитовых пород 57 . В мастерской Бэлэнешть культуры Ноуа ${ }^{58}$, находка которой дала более надежные, чем имевшиеся ранее, сведения о собственном раннем металлопроизводстве у соответствующего населения, представлены и типы, близкие к характерным для рышештского очага металлообработки (той же культуры ${ }^{59}$ ), в т.ч. непосредственно не представленный в лобойковско-голоуровском очаге металлообработки (бэлэнештский тип кинжалов, одними из прототипов которого, правда, в какой-то мере можно предположительно считать ножи с ромбоподобным перекрестием лобойковско-голоуровских, в том числе, тра-

52 См., напр.: Дергачев В. Клады поздней бронзы... С. 169, 174; С. 172, илл. 5: 8, 14; Дергачев В.А. Топоры-кельты поздней бронзы... С. 215, 220, 231, 237, 248, 251, 252, 254, 255, 259-260, 268-270, 276-278; С. 237, рис. $151: 8$, 14; С. 247, рис. $156: 33$, 56, 90a; С. 248, рис. $157: 28-31,52,54,55$; С. 257, рис. 159: 29, 55; Бочкарев В.С. Периоды развития... С.119-122, 127; С. 137, табл. 1: 55; С. 140, табл. 1: 73; С. 154, табл. І: комплексы 80, 110, типы 55, 73; С.151, рис. 5; С. 159, рис. 9: 12; 10: 18; Бочкарев В.С., Кашуба М.Т. Культурно-историческая ситуация... С. 209.

53 См., напр.: Сава Е., Бороффка Н. Новые находки бронзовых предметов эпохи поздней бронзы в Пруто-Днестровском междуречье // Revista Arheologică. 2013. S.n., vol. IX. Nr. 1. S. 178-179.

${ }_{54}$ См., напр.: Бочкарев В.С. Северопонтийское металлопроизводство эпохи поздней бронзы // Бочкарев В.С. Культурогенез и древнее металлопроизводство Восточной Европы. СанктПетербург: «Инфо Ол», 2010. С. 167, 168; Бочкарев В.С. Культурогенез и развитие металлопроизводства в эпоху поздней бронзы. (По материалам южной половины Восточной Европы) // Древние индо-иранские культуры Волго-Уралья (II тыс. до н.э.). Межвуз. сб. науч. тр. Самара: Изд-во СамГПУ, 1995. С. $117-121,123$.

55 Бочкарев В.С., Кашуба М.Т. Культурно-историческая ситуация... С. 209.

56 Черниенко Ю.А. Мастерская Бэлэнешть и связи традиций металлопроизводства культур бронзового века // Связи и взаимоотношения культур бронзового века Циркумпонтийского региона: новые данные и материалы. Тез. докл. круглого стола. Москва: ИА РАН, 2018. С. 80. Хотя у В.С. Бочкарева и Е.Ушурелу рышештские и красномаяцкие бронзы уверенно ассоциируются только с более поздними древностями (см., напр.: Бочкарев В.С. К вопросу об использовании серпов... С. 202, 203, 205; Uşurelu, E. Vârfurile de lance cu tocul scurt din perioada târzie a epocii bronzului din nordul Mării Negre // Revista Arheologică. 2016. S.n., vol. XII. Nr. 1-2. S. 50, 52, 57-58).

57 См., напр.: Шарафутдинова И.Н. Степное Поднепровье в эпоху поздней бронзы. Киев: Наук. думка, 1982. С. 136.

58 См., напр.: Дергачев В.А. Топоры-кельты поздней бронзы... С. 248, 252, 268, 276; С. 247, рис. 156: 56.

59 См., напр.: Бочкарев В.С. Культурогенез и развитие металлопроизводства... С. 118, 119, 121. 
диций) и такой, который может не иметь никакого отношения к лобойковскоголоуровской металлургии (безушковые наконечники копий с максимальным расширением пера без прорези ближе к втулке) ${ }^{60}$.

Более ярко черты рышештского очага металлообработки и в целом рышештскокрасномаяцко-дичевской зоны металлопроизводства выразились уже на последующей стадии, когда происходят дальнейшая переработка лобойковскоголоуровских традиций ${ }^{61}$, отход от последних. Была переработана, вероятно, и традиция производства бритв ${ }^{62}$.

Что касается таковых красномаяцкого и дичевского очагов металлообработки, то здесь пока можно предполагать лишь переработку лобойковско-голоуровских традицийб3 (возможно, не без влияния рышештского очага ${ }^{64}$ ), о непосредственных заимствованиях которых в данном случае у автора нет достоверных данных.

В.С. Бочкарев ограничивает бытование восточноевропейских бритв терешковского типа IV (лобойковско-дербеденовской) группой/периодом металлопроизводства, к которой относит, соответственно, комплекс из Комсомольского (Астраханская обл.) с бритвой с маленьким вырезом (рис. 1: 8), а также последний этап срубных древностей ${ }^{65}$. Отнесение В.В. Отрощенко этого кенотафа с находившимся там, в частности, позднейшим, по мнению исследователя, ножом срубного типа и погребения Высокое 6/1 (Запорожская обл.) с правобочной позицией скелета, являющейся, по мнению ученого, отклонением от классического срубного ритуала и присущей больше комплексам заключительного этапа БМСК, а также погребальному обряду черкаскульской и сусканской культур, и, в частности, с бритвой с символическим по глубине вырезом (рис. 1: 7) к позднейшим срубным погребениям66 не поддержали В.А. Подобед с соавторами, т.к. найденные там бритвы близки входившей в состав Дербеденевского клада, синхронного памятникам сабатиновской культуры I этапа, а не II, с которым В.В. Отрощенко синхронизирует поздние памятники БМСК 67.

Но ведь можно привести и аналогии, датирующиеся иначе. Так, литейная форма с поселения Капитаново-1 относится к более раннему времени, не говоря уже о бритвах ямной культуры (см. выше). А если выйти за пределы Восточной Европы, которыми в основном ограничиваются некоторые работы В.С.Бочкарева, то бритва с могильника Саргары (Казахстан) с относительно небольшим вырезом и, правда, с

\footnotetext{
60 См., напр.: Черниенко Ю.А. Мастерская Бэлэнешть... С. 79-80; ср., напр.: Черниенко Ю.А. Сабатиновская культура... С. 37.

61 См., напр.: Черниенко Ю.А. Мастерская Бэлэнешть... С. 80.

62 См., напр.: Бочкарев В.С. Этапы развития... С. 173, 174; С. 178, 180, 181, табл. 1: комплексы 80, 110, типы 55, 73; Дергачев В.А. Топоры-кельты поздней бронзы... С. 237, 248, 267, 275.

${ }^{63}$ См., напр.: Бочкарев В.С. Этапы развития... С. 173, 174; С. 178, 180, 181, табл. 1: типы 55, 73, комплекс 122; Ромашко В.А. Заключительный этап... С. 99; Дергачев В.А. Топоры-кельты поздней бронзы.... С. 236-237, 248-249, 267, 275.

${ }^{64}$ Ср.: Тутаева И.Ж. Металлические бритвы... С. 185.

65 Бочкарев В.С. Этапы развития... С. 171-173; С. 168, рис. 5: 10; С. 172, рис. 9: 12; С. 178, 180, 181, табл. 1: тun 55, комплекс 79; Бочкарев В.С., Кашуба М.Т. Культурно-историческая ситуация... С. 209.

66 Отрощенко В.В. Проблеми періодизації... С. 161-162. Н.М. Малов относит рассматриваемое погребение 16 Комсомольского могильника к срубно-хвалынской стадии III.1, к концу которой «срубная культура прекратила свое существование» (Малов Н.М. Памятники срубной культурноисторической области в Нижнем Поволжье: концептуальные основы культурогенеза // Древние культуры Юго-Восточной Европы и Западной Азии. Сборник к 90-летию и памяти Н.Я. Мерперта. Москва: Институт археологии РАН, 2014. С. 88).

67 Подобед В.А., Усачук А.Н., Цимиданов В.В. Погребение срубной культуры...
} 
кольцевидным упором68, отсутствие которого почему-то является для В.А. Подобеда, А.Н.Усачука и В.В.Цимиданова хронологическим маркером, даже в соответствии со схемами В.А.Дергачева и В.С.Бочарева, использованной В.А. Подобедом с соавторами ${ }^{69}$, В.С. Бочкарева и М.Т. Кашубы, позднее, чем Дербеденевский клад, культура Сабатиновка-І и в целом лобойковско-дербеденовская группа/период 70 .

В связи с находками федоровско-черкаскульской керамики на поселении второго (развитого), по мнению, в частности, В.В. Отрощенко, периода сабатиновской культуры Степовое, резонно и с этим памятником синхронизировать погребения с бритвами у Высокого и Комсомольского 71.

Так что, даже если в одной и той же верхней дате периодов БМСК-II и Сабатиновка-III72, которому B.В.Отрощенко противопоставляет переходный период (того же времени) от сабатиновской и бережновско-маевской срубной культур к белозерской ${ }^{73}$, сомневаться ${ }^{74}$, не исключено, что и некоторые восточноевропейские бритвы с небольшим вырезом (более того, позднейшие срубные древности) могут хронологически соответствовать ранней части Vпериода, по обновленной схеме B.С. Бочкарева, и быть близкими по времени, по крайней мере, некоторым бритвам с крупной выемкой. Хотя яркие комплексы лобойковско-голоуровского очага металлообработки относятся к раннесабатиновскому времени, о возможном продолжении функционирования этого очага позднее 75 могут предположительно свидетельствовать бритвы с небольшими вырезами.

В финале бронзового века география бритв с раздвоенными концами меняется теперь это, главным образом, Карпато-Дунайский регион. Преобладали бритвы с более или менее крупными вырезами, хотя известны и с небольшими76, а на поселении Костешты VII найдена литейная форма с негативом, в том числе, «возможно... бритвы»77 с усеченным концом (отнесено к «раннефракийским памятникам кишиневского типа») ${ }^{78}$. В.И. Клочко относит бритву с глубокой выемкой из т.н. «комплек-

\footnotetext{
${ }^{68}$ См., напр.: Дергачев В. Клады поздней бронзы... С. 172, илл. 5: 6.

69 Подобед В.А., Усачук А.Н., Цимиданов В.В. Погребение срубной культуры...

70 Дергачев В.А., Бочкарев В.С. Металлические серпы... С. 12-13, рис. 1; Бочкарев В.С., Кашуба М.Т. Культурно-историческая ситуация... С. 209; ср., напр.: Дергачев В.А. Топоры-кельты поздней бронзы... С. 237; Тутаева И.Ж. Металлические бритвы... С. 182, 185, 187, 189; Бочкарев В.С. Этапы развития... С. 173.

71 Отрощенко В.В. Проблеми періодизації... С. 161-162, 174.

72 См., напр.: Ромашко В.А. Заключительный этап... С. 390.

73 Отрощенко В.В. Проблеми періодизації... С. 174-175, 179, 180. На это уже приходилось реагировать (Черниенко Ю.А. Владимир Петрович Ванчугов - исследователь древностей позднего бронзового века Северного Причерноморья // Материалы по археологии Северного Причерноморья. Вып. 9. Одесса: «Печатный дом», «Фаворит», 2009. С. 390; Черниенко Ю.А. Некоторые впечатления о монографии В.А. Ромашко «Заключительный этап позднего бронзового века Левобережной Украины (по материалам богуславско-белозерской культуры)» // Археологія та етнологія півдня Східної Європи: [зб. наук. пр.]. Дніпро: Ліра, 2016. С. 211).

74 Черниенко Ю.А. Некоторые впечатления... С. 210.

75 См., напр.: Черниенко Ю.А. Сабатиновская культура... С. 21, 24, 31-36, 56-57.

${ }^{76}$ Cм., напр.: Boroffka N.G.O. Rasiermesser der Bronze- und Hallstattzeit aus Rumänien. S. 563-576; Клочко В.И., Козыменко А.В. Древний металл Украины. С. 323, ил. 29.

77 Подобед В.А., Усачук А.Н., Цимиданов В.В. Погребение срубной культуры...

${ }^{78}$ См., напр.: Дергачев В.А. Новые находки металлических предметов эпохи поздней бронзы на территории Молдавии // Археологические исследования в Молдавии (1977-1978). Кишинев: Штиинца, 1982. С. 133; С. 136, рис. 3: 9.
} 
са Доброванова», который в последнее время датирует ранним этапом чернолесской культуры (постсабатиновским временем) ${ }^{79}$, и более раннюю со сравнительно небольшим вырезом из Лобойковского клада к лобойковскому типу80. Как следует из вышеизложенного, автор этих строк по глубинам вырезов относит эти две бритвы к разным традициям, пусть, вероятно, и генетически связанным.

Широкое распространение бритв в сабатиновское время, пусть кое-где с переработкой первоначальной традиции, свидетельствует об активных межкультурных связях, в т.ч. дальних. Первая говорит об особенностях менталитета населения блока культур Сабатиновка-Ноуа-Кослоджень.

Если обратиться к типологии И.Ж. Тутаевой, то бритвы вязовковского типа отливались, в частности, в мастерской позднего этапа сабатиновской культуры Волошское 1 , но как будто бы не представлены в культурах Ноуа и Кослоджень ${ }^{81}$. Правда, В.А. Дергачев усматривает «максимальное сходство негативов из Фурен и «Нова Загора» с негативами бритв из Волошское 1 и Вязовок»82 (другого типа, по И.Ж. Тутаевой $\left.{ }^{83}\right)$.

Бритвы с крупными фигурными прорезями представлены в основном в культурах Ноуа и Кослоджень ${ }^{84}$, но автору этих строк неизвестны подобные изделия (вырбицкого типа, по классификации И.Ж. Тутаевой), которые бы достоверно относились к сабатиновской культуре 85 . В этом - одно из отличий последней не только от срубной культурно-исторической общности, но и от культур Ноуа и Кослоджень, красномаяцкого очага металлообработки - не только от лобойковскодербеденовской зоны металлопроизводства и вообе от Евразийской металлургической провинции, но и от рышештского и дичевского очагов рышештскокрасномаяцко-дичевской зоны Европейской провинции, контактной зоны (которую B.Н. Горбов не предусматривает, «присоединяя» к западному кругу валиковых культур или миру ${ }^{86}$ ) общности культур валиковой керамики - не только от восточной, но и от западной.

С версией распространения волго-уральской культурной провинции, образовавшейся, по мнению В.С. Бочкарева, «главным образом, за счет миграций... населения»

\footnotetext{
79 Клочко В.И., Козыменко А.В. Древний металл Украины. С. 322, 323.

80 Клочко B.I. Нові знахідки речей та комплексів гордіївського типу на Вінниччині // Гордіївський могильник. Вінниця, 2011. С. 250; С. 254, рис. 1: 4; С. 255, рис. 7.

81 Тутаева И.Ж. Металлические бритвы... С. 182, 184, 185, 190; С. 177, табл. 1: С6; С. 178, 179, рис. 1 : 15 ; С. 186,187 , рис. $4: 21$.

82 Дергачев В.А. Топоры-кельты поздней бронзы... С. 237.

83 См., напр.: Тутаева И.Ж. Металлические бритвы... С. 182, 184, 188, 190; С. 177, табл. 1: В2, С6; c. 181 , табл. 2: B2, C6; С. 186,187 , рис. $4: 3,21,22$. Не фигурирующая в работах И.Ж. Тутаевой бритва, представленная негативом на литейной форме из «Нова Загора», отличается от бритв, отливавшихся в мастерской Волошское 1 и в матрице из с. Вязовок, формой выреза (см., напр.: Дергачев В. Клады поздней бронзы... С. 172, илл. 5: 8, 10, 11).

84 См., напр.: Дергачев В. Клады поздней бронзы... С. 169, 172-174; С. 172, илл. 4; 5: 13, 14; с. 173, илл. 6: 11, 13, 14.

85 Отдельные находки бритв этого типа в лесостепной Украине (см., напр.: Тутаева И.Ж. Металлические бритвы... С. 184,190 ; С. 177, табл. 1 : D6; С. 182 , рис. 2: 3, 4; С. 183 , рис. 3:2, 3; С. 186, 187, рис. 4: 25, 26) связаны, скорее всего, с контактами соответствующего населения с носителями культуры Ноуа.

86 См., напр.: Горбов В.Н. К проблеме культурной атрибуции поселения на Белозерском лимане // Конвергенция и дивергенция в развитии культур эпохи энеолита - бронзы Средней и Восточной Европы. Ч.ІІ. Мат. конф. и дискуссии 21-25 августа 1995 г., Саратов. (Археологические изыскания. Вып. 25 (II)). Санкт-Петербург, 1995. С. 63, 68.
} 
волго-уральского очага культурогенеза, до юго-восточных предгорий Карпат (хоть бы и в IV период металлопроизводства) ${ }^{87}$ не согласуются, в том числе, восточноевропейские бритвы. Оснований для мыслей о волго-уральском происхождении этих изделий автор этих строк пока не видит. Наиболее древние подобные предметы (как будто бы за единственным исключением) найдены западнее Волго-Уралья88.

Вариант доведения культурной провинции волго-уральского очага культурогенеза только до Правобережной Украины ${ }^{89}$ представляется более удачным, особенно если отвлечься от бритв и некоторых других изделий. Влияние же первой (или же (для сабатиновского времени) восточной зоны общности культур валиковой керамики, входившей в систему Евразийской металлургической провинции ${ }^{90}$ ) проявляется, в частности, западнее 91.

\section{REFERENCES}

Bobrinskoi, A.A. (1913). Otchet o raskopkakh v Kievskoi gubernii v 1911 godu [Report on excavations in the Kiev province in 1911]. Izvestiia Imperatorskoi Arkheologicheskoi Komissii, 49, 89-100 [in Russian].

Bochkarev, V.S. (1995). Kulturogenez i razvitie metalloproizvodstva v epokhu pozdnei bronzy (po materialam yuzhnoi poloviny Vostochnoi Evropy] [The cultural genesis and the development of the metal production in the Late Bronze Age (by the materials from the southern half of Eastern Europe)]. Drevnie indo-iranskie kultury Volgo-Uralia (II tys. do n.e.). Samara: Izd-vo SamGPU, 114-123 [in Russian].

Bochkarev, V.S. (2010). Severopontiiskoe metalloproizvodstvo epokhi pozdnei bronzy [The North Pontic metal production of the Late Bronze Age]. In Bochkarev, V.S. Kulturogenez i drevnee metalloproizvodstvo Vostochnoi Evropy. Sankt-Peterburg: «Info Ol», 164-171 [in Russian].

Bochkarev, V.S. (2012). K voprosu ob ispolzovanii serpov i serpovidnykh orudii v stepnykh (skotovodcheskikh) kulturakh epokhi pozdnei bronzy Vostochnoi Evropy [To the question of the use of metal sickles and sickle-like tools in the Late Bronze Age steppe (nomadic) cultures of Eastern Europe]. Rossiiskii arkheologicheskii ezhegodnik, 2, 194-214 [in Russian].

Bochkarev, V.S. (2013). Srubno-alakulskaia zona metalloproizvodstva epokhi pozdnei bronzy [The Timber-Grave-Alakul metalworking zone of the Late Bronze Epoch]. Arkheologiia VostochnoEvropeiskoi stepi, (Vol. 10, pp. 75-83). Saratov: Tipografiia IP Beglakova E.S. [in Russian].

Bochkarev, V.S. (2015). Dinamika kulturno-istoricheskikh izmenenii v pozdnem bronzovom veke na yuge Vostochnoi Evropy (step i lesostep) [The dynamics of the cultural and historical changes in the Late Bronze Age in the south of Eastern Europe (steppe and forest-steppe)]. Abstracts of Papers: Kavkaz kak sviazuiushchee zveno mezhdu Vostochnoi Evropoi i Perednim Vostokom: dialog kultur, kultura dialoga (k 140-letiiu Aleksandra A. Millera), (pp.78-87). Sankt-Peterburg [in Russian and German].

Bochkarev, V.S. (2016). Periody razvitiia metalloproizvodstva epokhi pozdnei bronzy na yuge Vostochnoi Evropy [Periods of metal production development in the Late Bronze Epoch in the south of Eastern Europe]. Arkheologiia vostochno-evropeiskoi stepi, 12, Saratov: Tekhno-Dekor, 109-160 [in Russian].

Bochkarev, V.S. (2017). Etapy razvitiia metalloproizvodstva epokhi pozdnei bronzy na yuge Vostochnoi

87 Бочкарев В.С. Динамика культурно-исторических изменений в позднем бронзовом веке на юге Восточной Европы (степь и лесостепь) // Кавказ как связующее звено между Восточной Европой и Передним Востоком: диалог культур, культура диалога (к 140-летию Александра А. Миллера): Мат. Междунар. науч. конф. и Гумбольдт-лектория. Санкт-Петербург: ИИМК РАН; Евразийское отделение ДАИ; Невская Книжная Типография, 2015. С. 81-82, 84-86; Бочкарев В.С. Периоды развития... С. 113.

88 См., напр.: Кузнецов П.Ф., Мочалов О.Д. Особый тип металлических изделий... С. 295-297; Латынин Б.А. Молоточковидные булавки... С. 73; Братченко С.Н. До проблеми ранньобронзової індустpiï... C. $40,43$.

${ }^{89}$ Бочкарев В.С. Этапы развития... С. 162.

90 См., напр.: Черных Е.Н. Проблема общности... С. 87, 90, 94, 95.

91 См., напр.: Черниенко Ю.А. Сабатиновская культура... С. 19-23 и сл. 
Evropy [Stages in the development of metal production in the Late Bronze Age in the south of Eastern Europe]. Stratum plus, 2, 159-204 [in Russian].

Bochkarev, V.S. \& Kashuba, M.T. (2018). Kulturno-istoricheskaia situatsiia na yuge Vostochnoi Evropy nakanune epohki zheleza [Cultural and historical situation in the south of Eastern Europe on the eve of the Iron Age]. Stratum plus, 3, 207-220 [in Russian].

Bochkarev, V.S. \& Tutaeva, I.Zh. (2019). Proreznye nakonechniki kopii epokhi pozdnei bronzy Vostochnoi Evropy i sopredelnykh territorii [The Late Bronze Age openwork spearheads in Eastern Europe and beyond]. Stratum plus, 2, 167-222 [in Russian].

Bočkarev, V.S. \& Leskov, A.M. (1980). Jung- und spätbronzezeitliche Gussformen im nördlichen Schwarzmeergebiet [The Young and Late Bronze Age molds in the Northern Black Sea region]. Prähistorische Bronzefunde. XIX. 1. München: C. H. Beck'sche Verlagsbuchhandlung [in German].

Boroffka, N.G.O. (1997). Rasiermesser der Bronze- und Hallstattzeit aus Rumänien [The Bronze Age and Hallstatt razors from Romania]. Xpovos. Beiträge zur Prähistorischen Archäologie zwischen Nord- und Südosteuropa. Festschrift für Bernhard Hänsel. Internationale Archäologie. Studia honoraria. 1. Espelkamp: Verlag Marie Leidorf GmbH, 563-576 [in German].

Bratchenko, S.N. (1996). Do problemy rannobronzovoi industrii Skhidnoi Yevropy [To the problem of the Early Bronze Age industry of Eastern Europe]. Drevnie kultury Vostochnoi Ukrainy (problemy izucheniia i pravovoi okhrany arkheologicheskogo naslediia), (pp. 32-57). Lugansk: Izd-vo VUGU [in Ukrainian].

Brovender, Yu.M. (2000). Kapitanovo-1. Poselenie Pokrovskoi srubnoi kultury v severskodonetskom Levoberezhie [Kapitanovo-1. Settlement of Pokrovskaia Srubnaia culture on left bank of Severskii Donetz River]. Starozhytnosti stepovoho Prychornomoria i Krymu. (Vol. VIII, pp. 170-186). Zaporizhzhia: Dyke pole [in Russian].

Chernienko, Yu.A. (2009). Vladimir Petrovich Vanchugov - issledovatel drevnostei pozdnego bronzovogo veka Severnogo Prichernomoria [Vladimir Petrovich Vanchugov as a researcher of the Late Bronze Age antiquities of the Northern Pontic area]. Materialy po arheologii Severnogo Prichernomoria, (Vol. 9, pp. 382-397). Odessa: «Pechatnyj dom», «Favorit» [in Russian].

Chernienko, Yu.A. (2014). Sabatinovskaia kultura v sisteme drevnostei bronzovogo veka yuga Vostochnoi Evropy [The Sabatinovka culture in the system of the Bronze Age antiquities of the south of the Eastern Europe]. Stratum plus, 2, 15-112 [in Russian].

Chernienko, Yu.A. (2016). Nekotorye vpechatleniia o monografii V.A. Romashko «Zakliuchitelnyi etap pozdnego bronzovogo veka Levoberezhnoi Ukrainy (po materialam boguslavsko-belozerskoi kultury]» [Some impressions of the monograph of V.A. Romashko «The final stage of the Late Bronze Age of Left-Bank Ukraine (by the materials of the Boguslav-Belozersk culture»)]. Arkheolohia ta etnolohia pivdnia Skhidnoi Yevropy, (pp. 208-216). Dnipro: Lira [in Russian].

Chernienko, Yu.A. (2018). Loboikovsko-golourovskaia metallurgiia i naselenie stepnogo DunaiDnestrovskogo mezhdurechia [The Loboikovka-Golourov metallurgy and the population of the steppe Danube-Dniester interfluve]. Abstracts of Papers: Narody i kultury Nizhnego Dunaia $v$ drevnosti (g. Izmail, 23-26 avgusta 2018), (pp. 98-106). Izmail: Irbis [in Russian].

Chernienko, Yu.A. (2018). Masterskaia Belenesht i sviazi tradicii metalloproizvodstva kultur bronzovogo veka [The workshop Balanesti and connections of traditions of the metal production of the Bronze Age cultures]. Abstracts of Papers: Sviazi i vzaimootnosheniia kultur bronzovogo veka Tsirkumpontiiskogo regiona: novye dannye i materialy, (pp. 79-80). Moskva: IA RAN [in Russian].

Chernykh, E.N. (1976). Drevniaia metalloobrabotka na Yugo-Zapade SSSR [The ancient metalworking in the South-West of the USSR]. Moskva: Nauka [in Russian].

Chernykh, E.N. (1983). Problema obshchnosti kultur valikovoi keramiki v stepiakh Evrazii [The problem of the bead pottery cultures entity in the steppes of Eurasia]. In Bronzovyi vek stepnoi polosy Uralo-Irtyshskogo mezhdurechia, (pp. 81-99). Cheliabinsk: Bashkirskii gosuniversitet [in Russian].

Dergachev, V.A. (1982). Novye nakhodki metallicheskikh predmetov epokhi pozdnei bronzy na territorii Moldavii [The new finds of the metal objects of the Late Bronze Age on the territory of Moldavia]. In Arkheologicheskie issledovaniia v Moldavii (1977-1978). Kishinev: Shtiinca, 129-137 [in Russian].

Dergachev, V.A. (2011). Topory-kelty pozdnei bronzy Karpato-Podunavia (Kelty i serpy Nizhnego Podunavia) [Socket axes from Late Bronze Age of Carpathian-Danubian area. Vol. 2: Socket axes and sickles from Lower Danube area]. Kishineu: Izd.-Poligr. Firma «Tsentralnaia Tipografiia» [in Russian].

Dergachev, V. (2013). Klady pozdnei bronzy iz ss. Zhavgur i Otak v Respublike Moldova [Late Bronze 
Age hoards from the Javgur and Otac villages, Republic of Moldova]. Revista Arheologică, S.n., vol.IX. Nr. 2, 169-174 [in Russian].

Dergachev, V.A. \& Bochkarev, V.S. (2002). Metallicheskie serpy pozdnei bronzy Vostochnoi Evropy [The Late Bronze Age metal sickles of Eastern Europe]. Kishinev: Vysshaia Antropologicheskaia Shkola [in Russian].

Dmitriev, P.A. (1930). Liteinaia forma iz Shadrinskogo muzeia [The casting mold from the Shadrinsk museum]. In Tekhnika obrabotki kamnya i metalla. Trudy Sektsii arkheologii. Institut arheologii $i$ iskusstvoznaniya, 5, 53-60 [in Russian].

Gorbov, V.N. (1995). K probleme kulturnoi atributsii poseleniia na Belozerskom limane [To the problem of cultural attribution of the site on Belozerski liman]. Abstracts of Papers: Konvergentsiia $i$ divergentsiia v razvitii kultur epokhi eneolita - bronzy Srednei $i$ Vostochnoi Evropy (21-25 avgusta 1995 g., Saratov). (Arheologicheskie izyskaniia. 25 (II)), (pp. 52-72). Sankt-Peterburg [in Russian].

Jockenhövel, A. (1971). Die Rasiermesser in Mitteleuropa (Süddeutschland, Tschechoslowakei, Österreich, Schweiz) [The razors in the Central Europe (Southern Germany, Czechoslovakia, Austria, Switzerland)]. (Prähistorische Bronzefunde. VIII. 1). München: C.H. Beck'sche Verlagsbuchhandlung [in German].

Jockenhövel, A. (1980). Die Rasiermesser in Westeuropa (Westdeutschland, Niederlande, Belgien, Luxemburg, Frankreich, Großbritannien und Irland) [The razors in the Western Europe (West Germany, Netherlands, Belgium, Luxembourg, France, Great Britain and Ireland)]. (Prähistorische Bronzefunde. VIII. 3). München: C.H. Beck'sche Verlagsbuchhandlung [in German].

Klochko, V.I. (2006). Ozbroiennia ta viiskova sprava davnoho naselennia Ukrainy (5000-900 rr. do R.Kh.) [Arms and military affairs of the ancient population of Ukraine (5000-900 BC)]. Kyiv: ArtEk [in Ukrainian].

Klochko, V.I. (2011). Novi znakhidky rechei ta kompleksiv hordiivskoho typu na Vinnychchyni [The new finds of the things and complexes of Hordiivka type in Vinnytsia region]. In Hordiivskyi mohylnyk, (pp. 250-258). Vinnytsia [in Ukrainian].

Klochko, V.I. \& Kozymenko, A.V. (2017). Drevnii metall Ukrainy [The ancient metal of Ukraine]. Kiev [in Russian].

Korenevskii, S.N. (1978). O metallicheskikh nozhakh yamnoi, poltavkinskoi i katakombnoi kultur [About the metal knives of Pit-grave, Poltavka and Catacomb cultures]. Sovetskaia arkheologiia, 2, 3348 [in Russian].

Korniushin, G.I. (1971). Kurgany epokhi pozdnei bronzy u s. Staraia Toida Voronezhskoi oblasti [The mounds of the Late Bronze Age near the v. Staraia Toida, Voronezh Region]. Kratkie soobshcheniia Instituta arkheologii AN SSSR, 127, 78-85 [in Russian].

Kuznetsov, P.F. \& Mochalov, O.D. (2014). Osobyi tip metallicheskikh izdelii yamnoi kultury (po rezultatam rabot v Samarskoi doline) [Special type of metal products of Pit-grave culture (on the results of work in the Samara valley)]. Izvestiia samarskogo nauchnogo centra Rossiiskoi Akademii Nauk. Gumanitarnye nauki. (T. 16, No. 3, pp. 291-297). Samara: Izd-vo SNC RAN [in Russian].

Latynin, B.A. (1967). Molotochkovidnye bulavki, ikh kulturnaia atributsiia i datirovka [Hammer-shaped pins, their cultural attribution and dating]. (Arkheologicheskii sbornik, 9). Leningrad [in Russian].

Malov, N.M. (2014). Pamiatniki srubnoi kulturno-istoricheskoi oblasti v Nizhnem Povolzhie: konceptualnye osnovy kulturogeneza [The sites of the Timber-Grave cultural-historical area in the Lower Volga region: the conceptual foundations of the cultural genesis]. Drevnie kultury YugoVostochnoi Evropy i Zapadnoi Azii. Sbornik k 90-letiiu i pamiati N.Ya. Merperta. Moskva: Institut arheologii RAN, 84-92 [in Russian].

Otroshchenko, V.V. (2001). Problemy periodyzatsii kultur serednoi ta piznoi bronzy pivdnia Skhidnoi Yevropy (kulturno-stratyhrafichni zistavlennia) [The problems of the periodization of the cultures of the Middle and Late Bronze Age of the south of Eastern Europe (the cultural and stratigraphic comparisons)]. Kyiv: Instytut arkheolohii NAN Ukrainy [in Ukrainian].

Otroshchenko, V.V. (2002). Istoriia plemen zrubnoi spilnosti [The history of the tribes of Zrubna entity]. (Extended abstract of Doctor's thesis). Kyiv [in Ukrainian].

Podobed, V.A., Usachuk, A.N. \& Tsimidanov, V.V. (2010). Pogrebenie srubnoi kultury iz Komsomolskogo (Astrakhanskaia oblast): nekotorye aspekty osmysleniia [The burial of the TimberGrave culture from Komsomolsky (Astrakhan region): some aspects of understanding]. Arheologiia nizhnego Povolzhia: problemy, poiski, otkrytiia. Astrahan: Astrahanskij un-t. Retrieved from http://astraheritage.newsujet.com/Material/48/91 [in Russian].

Romashko, V.A. (2013). Zakliuchitelnyi etap pozdnego bronzovogo veka Levoberezhnoi Ukrainy (po 
materialam boguslavsko-belozerskoi kultury) [The final stage of the Late Bronze Age of Left-Bank Ukraine (by the materials of the Boguslav-Belozersk culture)]. Kiev: KNT [in Russian].

Sava, E. (2011). Neue Gussformenfunde der späten Bronzezeit aus dem Gebiet zwischen Prut und Dnestr [The new deposit of the casting molds of the Late Bronze Age from the area between Prut and Dniester]. Abstracts of Papers: Der Schwarzmeerraum vom Äneolithikum bis in die Früheisenzeit (5000-500 v.Chr.). Bd.2. Globale Entwicklung versus Lokalgeschehen. (Chişinău, Moldavien, 48 Oktober 2010), (pp. 178-187). Rahden/Westf.: Leidorf [in German].

Sava, E. (2016). K voprosu o liteinykh formakh dlia otlivki bronzovykh britv [On the issue of molds for casting bronze razors]. In Culturi, Procese şi Contexte în Arheologie. Volum omagial Oleg Leviţki la 60 de ani, (pp. 154-161). Chișinău [in Russian].

Sava, E. \& Boroffka, N. (2013). Novye nakhodki bronzovykh predmetov epokhi pozdnei bronzy v PrutoDnestrovskom mezhdurechie [The new finds of bronze objects of the Late Bronze Age in the PrutDniester interfluve]. Revista Arheologică. S.n., vol. IX. Nr. 1, 166-187 [in Russian].

Shaposhnikova, O.G. (1985). Yamnaia kulturno-istoricheskaia obshchnost [The Pit-Grave culturalhistorical entity]. In Arkheologiia Ukrainskoi SSR. Vol. 1: Pervobytnaia arkheologiia, (pp. 336-352). Kiev: Naukova Dumka [in Russian].

Sharafutdinova, I.M. (1973). Bronzolyvarna maisternia z s. Holovuriv na Kyivshchyni [The bronze foundry workshop from the v. Golovuriv in the Kyiv region]. Arkheolohiia, 12, 61-70 [in Ukrainian].

Sharafutdinova, I.N. (1982). Stepnoe Podneprovie v epokhu pozdnei bronzy [Steppe Dnieper in the Late Bronze Age]. Kiev: Naukova dumka [in Russian].

Tutaeva, I.Zh. (2014). Metallicheskie britvy epokhi pozdnei bronzy Vostochnoi Evropy [Metal razors in the Late Bronze Age of Eastern Europe]. Rossiiskii arkheologicheskii ezhegodnik, 4, 175-193 [in Russian].

Uşurelu, E. (2016). Vârfurile de lance cu tocul scurt din perioada târzie a epocii bronzului din nordul Mării Negre [Spearheads and darts with a short sheath of the Late Bronze Age in the Nothern Black Sea Region]. Revista Arheologică. S.n., vol. XII. Nr. 1-2, 44-60 [in Romanian].

\section{Yurii Chernienko}

(Odesa Archeological Museum of the National Academy of Sciences of Ukraine, Odesa, Ukraine)

ORCID: https://orcid.org/0000-0001-8710-7481

\section{On Two Traditions of Crafting Metal Razors with Bifurcated or Truncated Tips in the Bronze Age}

It seems fundamental, combining the findings of Ye.M. Chernykh and V.S. Bochkariov, to emphasize (besides chronology) on discordant cultural and territorial contexts for metal razors with bifurcated or truncated tips of two genetically related traditions of the Bronze Age, almost corresponding to the two types distinguished by V.S. Bochkariov. In Central and Western Europe, there is a noticeable tendency to enlarge razor cutouts with time. In more eastern regions in Sabatynivka time, razors having comparatively few earlier analogues with small cutouts of different depth, up to truncated tips, are mainly characteristic of: the Eurasian Metallurgical Province (in particular, Loboikivka-Derbeden zone of metallurgy); the eastern zone of the cultural circle of Valykova (relief-band) ceramics (in particular, BerezhnovkaMaivka Timber-grave culture); the Râșești-Chervonyi Maiak-Dichevo (mainly) zone of metallurgy in the Eurasian Metallurgical Province (razors with larger cutouts); partially, to some cultures of the western and contact zones of the cultural circle of Valykova ceramics, in particular, Noua, Sabatynivka, Coslogeni. In the Final Bronze Age, razors with small cutouts of different depth prevail in the Carpathian-Danube region.

Keywords: razors with bifurcated or truncated ends; crafting traditions; cultural and territorial contexts 